\title{
Behavioral characteristics of Chinese adolescents with dyslexia: The use of teachers' behavior checklist in Hong Kong
}

\author{
BOBY HO-HONG CHING \\ Oxford University \\ CONNIE SUK-HAN HO \\ University of Hong Kong \\ DAVID W. CHAN \\ Chinese University of Hong Kong \\ KEVIN K. H. CHUNG \\ Hong Kong Institute of Education \\ LAP-YAN LO \\ Hong Kong Shue Yan University
}

Received: November 15, $2011 \quad$ Accepted for publication: October 11, 2012

\begin{abstract}
ADDRESS FOR CORRESPONDENCE
Connie S.-H. Ho, Department of Psychology, C661, University of Hong Kong, Pokfulam Road, Hong Kong. E-mail: shhoc@hku.hk
\end{abstract}

\begin{abstract}
We developed the Hong Kong Specific Learning Difficulties Behavior Checklist for Junior Secondary School Students (BCL-JS) for teachers to rate the frequency of 52 reading-related behavioral characteristics of Chinese secondary school students. An item factor analysis based on ratings on 947 students yielded seven distinct dimensions. In a separate sample of 90 students, the seven constructs of the BCL-JS significantly correlated with students' performances on most literacy and reading-related cognitive measures, and differentiated adolescents with or without dyslexia. Discriminant analysis showed that the BCL-JS had a high rate of correct classification (82.2\%). These findings support that the BCL-JS is a reliable screening tool for Chinese junior secondary school students at risk for dyslexia.
\end{abstract}

Research has demonstrated that the difficulties in phonological processing represent the core problems of individuals with developmental dyslexia in alphabetic languages (e.g., Bradley \& Bryant, 1978; Hulme \& Snowling, 1992; Olson,

(C) Cambridge University Press 2013 0142-7164/13 \$15.00 
Rack, \& Forsberg, 1990; Shankweiler, Liberman, Mark, Fowler, \& Fischer, 1979). Although phonological awareness has also been associated with the reading development of Chinese children (e.g., Chen et al., 2004; Ho \& Bryant, 1997a; Siok \& Fletcher, 2001), the most dominant type of cognitive deficits of Chinese dyslexic readers is not phonological awareness but morphological awareness, rapid naming, and visual-orthographic processing (Chung, Ho, Chan, Tsang, \& Lee, 2011; Ho, Chan, Lee, Tsang, \& Luan, 2004; Ho, Chan, Tsang, \& Lee, 2002a; McBride-Chang, Wagner, Muse, Chow, \& Shu, 2005; Shu, McBride-Chang, Wu, $\&$ Liu, 2006). The unique characteristics of Chinese script may contribute to these research findings. Chinese is a morphosyllabic system (DeFrancis, 1989; Leong, 1973; Mattingly, 1972). Each basic character is associated with a morpheme (meaning unit) and represents a spoken syllable. Whereas the number of spoken syllables is limited in Chinese, these syllables are associated with a larger number of regularly used characters of different meanings. For example, in Cantonese, a syllable /seoi/ can have 6 tones, which represent different meanings: /seoil/ 需 (need), /seoi2/ 水 (water), /seoi3/歲 (age), /seoi4/誰 (who), /seoi5/絮 (cotton), and /seoi6/睡 (sleep). There are around 1,700 tonal syllables that are mapped onto 4,500 commonly used Chinese characters (Liu, Chuang, \& Wang, 1975; Qian, Lee, \& Soong, 2004), making the ability to distinguish homophones particularly important in reading Chinese (e.g., McBride-Chang, Chow, Zhong, Burgess, \& Hayward, 2005; McBride-Chang, Shu, Zhou, Wat, \& Wagner, 2003; Shu et al., 2006).

In addition to the relatively large number of homophones, the visualorthographic structure of the Chinese script is also distinct from alphabetic languages. Each Chinese character is composed of strokes arranged in accordance with a set of conventional rules. For instance, similar stroke patterns such as 士 /si6/ (soldier), 土/tou2/ (soil), 上/soeng5/ (up), and 工 /gung1/ (work) have different sounds and represent distinct meanings. There is some evidence suggesting that visual-orthographic skill is important for individuals to read Chinese (e.g., Ho \& Bryant, 1997b; Huang \& Hanley, 1997; McBride-Chang, Wagner, et al., 2005). Training in morphological skills such as, through extensive games and exercises on combining different morphemes to form different Chinese compound words, was found to be effective for enhancing Chinese children's reading performance (Chow, McBride-Chang, Cheung, \& Chow, 2008). Explicit instructions that reminded learners of the radical structures also enhanced the memorization of Chinese characters (Ho, Wong, \& Chan, 1999; Taft \& Chung, 1999; Wang, Liu, \& Perfetti, 2004).

The importance of early intervention for dyslexia has underscored the need for reliable and valid screening instruments. In one of the Chinese communities, Hong Kong, the incidence rate of dyslexia was less than $1 \%$, which was much lower than would be expected from figures reported around the world (see Ho, Chan, Tsang, \& Lee, 2000a; Salter \& Smythe, 1997). One probable reason for this low incidence is the lack of appropriate instruments for the identification of dyslexic cases. Since 2000, the Hong Kong Tests of Specific Learning Difficulties in Reading and Writing for primary school students Ho et al., 2000a) and for junior secondary school students (HKT-JS; Chung, Ho, Chan, Tsang, \& Lee, 2007) were developed to serve the purpose of identifying dyslexic individuals. The development of these instruments was based on research studies conducted with Chinese dyslexic 
individuals. These studies showed that Chinese dyslexic individuals were weak at multiple cognitive areas, including visual-orthographic skills, rapid naming, morphological awareness, verbal memory, and phonological awareness, with the first three being their major difficulties (Chung et al., 2011; Ho et al., 2002a, 2004; Shu et al., 2006). Because doing comprehensive assessments on each of these areas with every child is not cost effective, using checklists based on students' overt behavior associated with dyslexia could be a more efficient alternative for initial screening. The Hong Kong Specific Learning Difficulties Behavior Checklist for Primary School Pupils is a screening tool for teachers to identify primary school pupils at risk for dyslexia (Chan, Tsang, \& Lee, 2002b; Ho, Chan, Tsang, \& Lee, 2000b). While Chan, Ho, Tsang, Lee, and Chung (2004) found 10 behavioral characteristics that could distinguish children with dyslexia from those without dyslexia, ratings on children's social/emotional behavior failed to differentiate their dyslexic status. There is evidence suggesting that the behavioral differences in the emotional and social areas between individuals with and without dyslexia may assume greater importance when they become adolescents (Benasich, Curtiss, \& Tallal, 1993; Chan \& Ho, 2002; McConaughy \& Ritter, 1985). The Hong Kong Behavior Checklist of Specific Learning Difficulties in Reading and Writing for Junior Secondary School Students (BCL-JS) was published recently to help teachers identify young adolescents at risk for dyslexia (Ho et al., 2009). The purpose of this study was to (a) confirm the reliability and validity of the BCL-JS, (b) explore the relationships between the reading-related behavioral characteristics assessed by the checklist and the profiles of literacy and cognitive skills measured by the HKT-JS in Hong Kong Chinese young adolescents, and (c) investigate whether behavioral characteristics measured by the BCL-JS could differentiate adolescents with dyslexia from those without dyslexia.

\section{THE USE OF BEHAVIOR CHECKLISTS}

Neurological and cognitive deficits of an individual manifested at the behavioral level collectively as signs or patterns might suggest whether he or she is at risk for dyslexia. Researchers and practitioners consider it useful to construct a checklist as a guideline to observe and identify individuals with dyslexia. Screening has been widely used in the field of medicine as well as education (Glascoe, Martin, \& Humphrey, 1990; Lichtenstein \& Ireton, 1984). A two-stage assessment process is recommended, including an initial screening and a follow-up comprehensive evaluation (Ho, 2010). The purpose of the initial screening stage is to designate individuals who are most likely to have problems, and an extensive follow-up assessment will serve to confirm their needs for special services and to make appropriate recommendations.

Over the years, considerable evidence has been amassed for the effectiveness of the use of behavioral checklists to assess children's likelihood of acquiring diverse types of disorders (see Mash \& Wolfe, 2002; Wagner, 2003). The majority of these behavior checklists are rating scales that are global or broad spectrum in nature. These scales require parents and teachers to indicate the presence of some general behaviors or the frequency and intensity of these behaviors of the children (Mash $\&$ Terdal, 1997). An example of these comprehensive measures is the Achenbach 
System of Empirically Based Assessment, which includes the Child Behavior Checklist and the Teacher's Report Form (see Achenbach \& Rescorla, 2001a, 2001b), and the Behavior Assessment System for Children, which includes Parent Rating Scales and Teacher Rating Scales (see Reynolds \& Kamphaus, 1992).

Apart from these global behavior checklists, some others have been created specifically to identify children with learning difficulties. Whereas broadband instruments, for example, the Myklebust Pupil Rating Scale (see Margolis, Sheridan, \& Lemanowicz, 1981) and the Windward Rating Scale (see Hamada \& Tomikawa, 1986), were available for screening students with learning difficulties, only a limited number of screening tools designed specifically for dyslexia have been developed on the basis of reading-related behavioral characteristics. A notable example is the Dyslexia Screening Instrument (Coon, Waguespack, \& Polk, 1994), which consists of 33 statements aimed at identifying students who display behavior significantly associated with reading, spelling, writing, or language processing difficulties. Although behavioral rating scales offer many benefits to the assessment process including administration convenience and the possibility of getting a large pool of normative data to establish developmental deviance (Shelton \& Barkley, 1994), there is still a lack of early screening tools available for dyslexia, which calls for an empirical investigation into this issue.

\section{BEHAVIOR CHECKLISTS FOR SCREENING DYSLEXIA IN CHINESE}

Despite the clear value of early identification for dyslexia, viable identification tools in Chinese have not been available until recently in Hong Kong. Suspected cases of dyslexia were referred to government educational psychologists for formal assessment and special services provision. In earlier years, the assessment of dyslexia was chiefly based on individuals' performance on a full IQ test; general tests assembled to assess word copying, word matching, and word reading; and the Bender-Gestalt Test (Bender, 1946). Educational psychologist would refer to individuals' performance on these tests, coupled with additional information from educational history, sample scripts of homework, dictation, and free writing, to determine whether one should be classified as dyslexic. In recent years, the procedures and criteria of identification have been modified with the development of the Hong Kong Tests of Specific Learning Difficulties in Reading and Writing for primary school students and the HKT-JS. These instruments facilitate professionals to perform comprehensive assessments for Cantonese-speaking children and young adolescents on multiple areas, including literacy skills and cognitive deficits in phonological skills, rapid naming, and orthographic knowledge (Ho et al., 2002a).

Although more accurate case identifications on the basis of specific readingrelated cognitive deficits are conducive to more appropriate interventions, the full diagnostic assessment is time consuming and financially prohibitive if all suspected cases are to be assessed comprehensively. Thus, a cost-effective and valid screening instrument for dyslexia that can be easily administered by teachers would constitute a momentous contribution to the armamentarium of assessment tools available to professionals in educational settings. The advantage of teacher ratings is that they are based on daily observations made in relatively standardized classrooms. Moreover, the ratings are formed by directly comparing children of 
the same developmental level. Hence, the Difficulties Behavior Checklist has been developed and empirically validated for teachers to perform initial screening of dyslexic cases among primary school pupils (Ho et al., 2000a; Ho, Chan, Tsang, \& Lee, 2002b; Chan, Ho, Tsang, Lee, \& Chung 2003, 2004, 2010). In their study, primary school teachers rated on the checklist the frequency of 65 reading-related behavioral characteristics of their students. They showed that 10 behavioral characteristics could differentiate children with dyslexia from those without dyslexia. These characteristics included general performance, reading, dictation, writing, mathematics, language, memory, concentration, sequential ability, and spatial orientation.

\section{BCL-JS}

In addition to developing a quick screening tool for primary school students, there is also a need to construct and validate one to help secondary school teachers identify young adolescents at risk for dyslexia and make corresponding remediation. Because notable physical and psychological changes emerge as children become adolescents, one should take developmental differences into consideration when designing a valid behavior checklist for screening young adolescents at risk for dyslexia.

Dyslexic individuals are at risk for failure not only academically but also socially and emotionally. These social and emotional difficulties may be exacerbated as children enter young adolescence. There is considerable evidence showing that the hardship in learning experienced by dyslexic individuals is associated with emotional, social, and behavioral problems in everyday life (for reviews, see Bender, 1987; Gresham, 1982; Sabornie, 1985). The frustration of prolonged failure on a range of academic subjects would result in feelings of anxiety and insecurity (Boetsch, Green, \& Pennington, 1996; Richman, Stevenson, \& Graham, 1982), which may in turn pose profound negative influence upon these individuals' selfimage (Burden, 2005; Humphrey \& Mullins, 2002; Undheim, 2003), emotions (Beitchman \& Young, 1997; Boetsch et al., 1996; Heiervang, Stevenson, Lund, \& Hugdahl, 2001), as well as acceptance and adjustment among peers (Bender \& Wall, 1994; Hellendoorn \& Ruijssenaars, 2000; LaGreca \& Stone, 1990). In dealing with problems, some dyslexic individuals may release their tensions through aggressive and antisocial behavior (McConaughty, 1986; McKinney, 1989; McKinney \& Feagans, 1984; Sanson, 2006).

Empirical evidence showed that these emotional and social problems were more prevalent among adolescents than among children in general, even though they had no learning disabilities. Blyth, Simmons, and Bush (1978), for example, found that junior adolescents generally expressed lower self-esteem than their younger counterparts in upper elementary schools. In terms of social behavior, Simmons, Blyth, Van Cleave, and Bush (1979) revealed a lack of social integration among early adolescents in middle and junior high schools, and they indicated a higher prevalence rate of victimization among students in middle high schools than those in upper elementary school grades.

Similar findings were obtained by Benasich et al. (1993), who examined children with language disorders. The researchers suggested that children would exhibit 
more observable behavioral and emotional problems as they matured. They indicated that almost one third of the language-impaired children scored in the clinically significant range on the Achenbach Child Behavior Checklist (Achenbach \& Edelbrock, 1983) at age 8 as compared with $11 \%$ at age 4 . McConaughty and Ritter (1985) used the same Child Behavior Checklist (Achenbach \& Edelbrock, 1983 ) to examine social competence and behavioral problems in learning disabled boys aged 6-16. They found that the older boys exhibited patterns of problematic behavior that were not evident in their younger counterparts. Chan and Ho (2002) also showed that Chinese adolescents with dyslexia (Primary 4-Form 1) displayed higher levels of emotional and behavioral difficulties than did dyslexic children (Primary 1-Primary 3). Using the Child Behavior Checklist (Achenbach, 1991; Achenbach \& Edelbrock, 1983), parents of dyslexic adolescents reported their children having higher scores on depression, withdrawal problems, social difficulties, externalizing problems, and aggressive behavior, in comparison to that reported by parents of younger dyslexic children (Chan \& Ho, 2002).

A recent study conducted by Chan et al. (2004) showed that children's social/ emotional behavior observed by teachers was not sensitive enough to differentiate children with dyslexia from those without dyslexia, consistent with past findings that children with and without learning disabilities could not be differentiated in terms of emotional characteristics (Jorm, Share, Matthews, \& McLean, 1986). However, in light of the evidence suggesting that more emotional and social problems would surface as children entered early adolescence (Benasich et al, 1993; Chan \& Ho, 2002; McConaughy \& Ritter, 1985), teachers' ratings on these social/emotional domains may be useful for predicting dyslexic status of young adolescents.

\section{THE PRESENT STUDY}

After a review of available behavior checklists (e.g., the Dyslexia Screening Instrument and the Hong Kong Specific Learning Difficulties Behavior Checklist for Primary School Pupils), relevant literature, and consultation with experienced frontline professionals in Hong Kong, we developed the 52-item BCL-JS. This research aimed to test the use of the checklist as a teacher screening tool for Chinese young adolescents with dyslexia. The objectives of this study were to (a) provide evidence to support the reliability and validity of the BCL-JS, (b) explore the relationships among the reading-related behavioral characteristics assessed by the checklist and the profiles of literacy and cognitive skills of the adolescents measured by the HKT-JS, and (c) investigate whether the BCL-JS could significantly predict adolescents' dyslexic status.

\section{METHOD}

\section{Participants and procedures}

In this study, data were collected from teachers and students in 33 secondary schools in Hong Kong. The schools were selected on the basis of stratified random sampling and were representative of the secondary school distribution in Hong 
Kong. In the first phase of data collection, secondary school teachers of the Chinese language subject were asked to rate on the BCL-JS a group of students who were randomly selected in their class. Teachers could consult other teachers on the behaviors of specific students when they encountered problems in rating any items of the checklist. Students who had immigrated to Hong Kong from Mainland China less than 1 year before were excluded because they might speak various dialects and have received different levels and types of education before coming to Hong Kong. Teachers' ratings on the reading-related behavioral characteristics of 947 students were obtained, of which $49.8 \%$ were boys and $50.2 \%$ were girls.

Due to resource constraint, not all 947 students were assessed in the second phase of data collection. On the basis of the ratings on the BCL-JS, students were divided into three groups (low score group, average score group, and high score group). Thirty students were randomly selected from each group for a second phase assessment with the HKT-JS, and their IQs were estimated by the vocabulary subtest of the Hong Kong Wechsler Intelligence Scale for Children (Psychological Corporation, 1981) in order to diagnose whether they had dyslexia. The reason for oversampling the students with low scores on the BCL-JS beyond the proportion of score distribution was to ensure that we would have a big enough sample of students potentially at risk with dyslexia for calculating the sensitivity and specificity indices and determining the cutoff point. Only students with average or above average intelligence were included in the second phase assessment. Teachers were also asked to report if the students had any disabilities (e.g., autism spectrum disorders or attention-deficit/hyperactivity disorder). The present sample did not include students with any comorbid conditions. The final sample consisted of 90 students who met the above criteria and completed all the assessment, including 48 boys and 42 girls aged between 11 and 15 years $(M=13.32$ months, $S D=$ 1.04).

\section{Measures}

The BCL-JS is a 52-item checklist of student reading-related behavioral characteristics that can be observed in classrooms by teachers. The initial design of the checklist covered sevem reading-related behavioral characteristics that include Chinese reading ability (9 items; e.g., "do not recognize common words"); Chinese writing ability, that is, the ability to write Chinese characters in appropriate ways, such as whether they put a stroke in the right place in the character (12 items; e.g., "make more spelling/writing errors for characters with more strokes than age peers"); Chinese composition ability, that is, the ability to use words to produce sentences, paragraphs, and passages (4 items; e.g., "the performance in composition is worse than that in verbal expression"); memory and organization ability (9 items; e.g., "easily forget things that have been learned); attention (3 items; e.g., "get distracted easily"); learning motivation (6 items; e.g., "do not try to learn new things"); and social/emotional adjustment (9 items; e.g., "have swinging mood"). Teachers indicated their observations of the frequencies of their students' behavior on a 5-point scale ranging from 1 (never observed) to 5 (often observed). 
The HKT-JS is a standardized test for diagnosis of Chinese adolescents with dyslexia. The norm was established with a representative sample of 709 adolescents aged from 11 years 7 months to 15 years 6 months recruited from high-, medium-, and low-ability schools of different districts in Hong Kong. There are 13 subtests in the HKT-JS: 5 literacy subtests (Chinese word reading, one minute reading, Chinese word dictation, ten minute reading, and reading comprehension), 2 rapid naming subtests (digit rapid naming and letter rapid naming), 2 morphological awareness subtests (morpheme discrimination and morpheme production), 2 phonological memory subtests (backward digit span and nonword repetition), and 2 orthographic knowledge subtests (Chinese characters matching and delayed copying). The development of this test was based on research studies conducted with Chinese dyslexic individuals. These studies showed that Chinese dyslexic individuals were weak at multiple cognitive areas, including visual-orthographic skills, rapid naming, morphological awareness, verbal memory, and phonological awareness, with the first three being their major difficulties (Chung et al., 2011; Ho et al., 2002a, 2004; Shu et al., 2006).

The scores of the 13 subtests were combined to give five composite scores on the domains of literacy, rapid naming, morphological awareness, phonological memory, and orthographic knowledge. Students who scored 7 or below on three or more out of the five literacy measures plus on one or more of the cognitive skill domains were classified as dyslexic.

\section{RESULTS}

\section{Dimensions of reading-related behavioral characteristics in BCL-JS}

An exploratory factor analysis using principal-axis estimation with a varimax rotation was conducted to assess the underlying factor structure of the BCL-JS. An initial estimation yielded seven factors with eigen values exceeding 1, accounting for $71.43 \%$ of the total variance. The seven-factor solution was interpretable and was regarded as an adequate representation of the data to describe this sample of Chinese students. Table 1 presents the factor loadings of individual items of the scale. Names were chosen for all seven factors based on the content of the items that loaded on the same factor. The 9 items that comprised Factor 1, the reading subscale, represented behavior reflecting students' reading abilities. Factor 2, the writing subscale, included 12 items related to students' performance in writing domains. The 4 items that loaded on Factor 3, the composition subscale, reflected students' proficiency in composition. Factor 4, the memory and organization ability subscale, included 9 items that described students' ability to memorize and organize materials in their mind. Factor 5, the learning motivation subscale, included 9 items that assessed students' motivation to learn. Factor 6 and Factor 7 were labeled as the internalizing behavior subscale ( 4 items) and the externalizing behavior subscale (5 items), respectively.

Although the factor loadings of several items were relatively low, we would like to keep these items in the checklist. Students without dyslexia scored significantly higher than dyslexic students on every item in the checklist (with results described in the following sections). In other words, although some of the items have low 
Table 1. Factor loadings for the exploratory factor analysis (varimax rotation) of the Behavior Checklist of Specific Learning Difficulties in Reading and Writing for Junior Secondary School Students

\begin{tabular}{|c|c|}
\hline Items & $\begin{array}{l}\text { Factor } \\
\text { Loadings }\end{array}$ \\
\hline \multicolumn{2}{|l|}{ Reading subscale (Cronbach $\alpha=0.93$ ) } \\
\hline 1. mix up characters easily & 0.76 \\
\hline 2. do not recognize common words & 0.76 \\
\hline 3. read words wrongly & 0.75 \\
\hline 4. confuse words close in pronunciation & 0.71 \\
\hline 5. use fingers to help reading & 0.49 \\
\hline 6. misunderstand sentences with more complicated structures & 0.61 \\
\hline 7. misse words when reading & 0.66 \\
\hline 8. have difficulties in reading a passage fluently & 0.61 \\
\hline 9. read worse than age peers & 0.62 \\
\hline \multicolumn{2}{|l|}{ Writing subscale (Cronbach $\alpha=0.94)$} \\
\hline 10. have poor dictation performance & 0.23 \\
\hline 11. not willing to do homework that involves copying & 0.38 \\
\hline 12. need more time to spell/write than age peers & 0.42 \\
\hline 13. have difficulties in spelling/writing characters within a designated space & 0.75 \\
\hline 14. show irregular size of characters when spelling/writing & 0.81 \\
\hline 15. show irregular distances between characters when spelling/writing & 0.77 \\
\hline 16. miss words when spelling/writing & 0.61 \\
\hline $\begin{array}{l}\text { 17. make more spelling/writing errors for characters with more strokes than } \\
\text { age peers }\end{array}$ & 0.60 \\
\hline 18. show mistakes in spelling/copying & 0.25 \\
\hline 19. have uncommon mistakes in spelling specific components of characters & 0.31 \\
\hline 20. spell words in wrong orders & 0.30 \\
\hline 21. use semantically similar words wrongly & 0.19 \\
\hline \multicolumn{2}{|l|}{ Composition subscale (Cronbach $\alpha=0.85$ ) } \\
\hline 22. Performance in composition worse than that in verbal expression & 0.17 \\
\hline 23. Performance in composition worse than age peers & 0.35 \\
\hline 24. miss punctuation in composition & 0.58 \\
\hline 25. misuse punctuation in composition & 0.49 \\
\hline \multicolumn{2}{|l|}{ Memory and organization ability subscale (Cronbach $\alpha=0.94)$} \\
\hline 26. easily forget things that have been learned & 0.55 \\
\hline 27. cannot follow a series of instructions & 0.58 \\
\hline 28. have difficulties in remembering things related to schools & 0.54 \\
\hline 29. cannot remember information just heard & 0.63 \\
\hline 30. forget to bring books to schools & 0.51 \\
\hline 31. need more time to express words or sentences than age peers & 0.58 \\
\hline 32. lack of coherence in speech & 0.59 \\
\hline 33. cannot explain thoughts systematically & 0.57 \\
\hline 34. cannot integrate others' opinion to reach conclusion during discussion & 0.63 \\
\hline \multicolumn{2}{|l|}{ Learning motivation subscale (Cronbach $\alpha=0.95)$} \\
\hline 35. need others' reminders to finish homework & 0.49 \\
\hline 36. get distracted easily & 0.57 \\
\hline 37. make mistakes because of not paying attention & 0.53 \\
\hline 38. have no expectations in school performances & 0.75 \\
\hline
\end{tabular}




\begin{tabular}{lc}
\hline \hline \multicolumn{1}{c}{ Items } & $\begin{array}{c}\text { Factor } \\
\text { Loadings }\end{array}$ \\
\hline 39. believe that s/he cannot do well even paying much effort & 0.73 \\
40. have no interest in classroom activities & 0.75 \\
41. dare not to ask questions when problems arise & 0.79 \\
42. do not reflect on their problems in learning & 0.81 \\
43. do not try to learn new things & 0.81 \\
Internalizing behavior subscale (Cronbach $\alpha=0.83)$ & \\
44. get depressed easily & 0.69 \\
45. have low self-esteem and lack confidence & 0.65 \\
46. get anxious easily & 0.71 \\
47. prefer to be alone, not sociable & 0.69 \\
Externalizing behavior subscale (Cronbach $\alpha=0.85)$ & 0.55 \\
48. have swinging moods & 0.55 \\
49. skip schools without reasons & 0.75 \\
50. like to attract others' attention & 0.77 \\
51. have conduct problems & 0.76 \\
52. not obedient and rebel against teachers/seniors & \\
Total variance = 71.43\% & \\
\hline \hline
\end{tabular}

factor loadings, all of them could significantly differentiate students with dyslexia from those without. Moreover, excluding them does not further strengthen the sensitivity of the checklist. Given that the most important function of a screening tool is its ability to identify at-risk students, we decided to keep these items in the checklist.

\section{Internal consistency reliability}

Scale internal consistency reliability was determined by calculating Cronbach coefficient alphas. The Cronbach $\alpha$ of the entire BCL-JS was 0.91. The internal consistency of each subscale was also assessed using Cronbach alpha, indicating a high reliability among all subscales (reading $=0.93$, writing $=0.94$, composition $=$ 0.85 , memory and organization ability $=0.94$, learning motivation $=0.95$, internalizing behavior $=0.83$, and externalizing behavior $=0.85$ ).

\section{Classification of students as dyslexic/nondyslexic}

To examine the relationships between reading-related behavioral characteristics and literacy/cognitive skills, a correlation matrix was computed. Table 2 presents the pattern of correlations between the five composite scores of literacy/cognitive skills scored in the direction of positive abilities and the seven empirical scale scores of reading-related behavioral characteristics scored in the direction of 
Table 2. Means and standard deviations of composite scores on literacy and cognitive skills of young adolescents and their correlations with scales of reading-related behavioral characteristics $(N=90)$

\begin{tabular}{|c|c|c|c|c|c|c|c|}
\hline & \multicolumn{7}{|c|}{ Correlation Matrix } \\
\hline & $M$ & $S D$ & LT & $\mathrm{RN}$ & MA & PM & $\mathrm{OK}$ \\
\hline \multicolumn{8}{|c|}{ HKT-JS Literacy and Cognitive Skills } \\
\hline LT & 8.93 & 3.09 & & & & & \\
\hline $\mathrm{RN}$ & 8.70 & 3.40 & $.61 * *$ & & & & \\
\hline MA & 9.12 & 2.98 & $.75^{* *}$ & $.35 * *$ & & & \\
\hline PM & 9.52 & 2.48 & $.47 * *$ & $.39 * *$ & $.34 * *$ & & \\
\hline OK & 10.02 & 2.32 & $.40 * *$ & .17 & $.36 * *$ & $.36 * *$ & \\
\hline \multicolumn{8}{|c|}{ BCL-JS Reading-Related Behavioral Characteristics } \\
\hline Reading & 2.04 & 0.74 & $-.64 * *$ & $-.35^{* *}$ & $-.58 * *$ & $-.29 * *$ & -.20 \\
\hline Writing & 1.92 & 0.76 & $-.60 * *$ & $-.35 * *$ & $-.45^{* *}$ & $-.25^{*}$ & -.18 \\
\hline Composition & 2.23 & 0.86 & $-.60 * *$ & $-.35 * *$ & $-.41 * *$ & $-.34 * *$ & -.18 \\
\hline \multicolumn{8}{|l|}{ Memory and organization } \\
\hline ability & 2.20 & 0.82 & $-.60 * *$ & $-.36^{* *}$ & $-.50 * *$ & $-.34 * *$ & $-.21 *$ \\
\hline Learning motivation & 2.56 & 0.93 & $-.54 * *$ & $-.36 * *$ & $-.40 * *$ & $-.31 * *$ & -.18 \\
\hline Internalizing behavior & 1.87 & 0.70 & $-.44 * *$ & $-.32 * *$ & $-.44 * *$ & $-.28 * *$ & .04 \\
\hline Externalizing behavior & 1.63 & 0.70 & $-.47 * *$ & $-.31 * *$ & $-.31 * *$ & $-.21 *$ & -.07 \\
\hline
\end{tabular}

Note: The HKT-JS scores were standardized scores adjusted for age $(M=10, S D=$ 3). The maximum for each BCL-JS score was 5. HKT-JS, Hong Kong Test of Specific Learning Difficulties in Reading and Writing for Junior Secondary School Students; LT, literacy; RN, rapid naming; MA, morphological awareness; PM, phonological memory; OK, orthographic knowledge; BCL-JS, Behavior Checklist of Specific Learning Difficulties in Reading and Writing for Junior Secondary School Students.

$* p<.05$ (two tailed). $* * p<.001$.

problems or difficulties. The means and standard deviations of the seven scale scores of behavioral characteristics for the students are also included in the table. The correlation matrix indicated that all seven behavioral characteristics had significant negative correlations with literacy and all reading-related cognitive abilities (except orthographic knowledge), that is, rapid naming, phonological memory, and morphological awareness.

To investigate whether teachers' ratings with the scale could effectively differentiate students with dyslexia from those without dyslexia as defined by test scores of the HKT-JS, we conducted a multivariate analysis of variance on the seven subscales' scores of behavioral characteristics as dependent variables using the dyslexia case-noncase dichotomy as the grouping variable. The results showed significant differences for the seven scores of reading-related behavioral characteristics, Wilks $\lambda=0.58, F(7,82)=8.58, p<.001, \eta^{2}=0.42$. Followup univariate analyses of variance were then conducted on each of the seven 
Table 3. Scores on Behavior Checklist of Specific Learning Difficulties in Reading and Writing for Junior Secondary School Students reading-related behavioral characteristics for young adolescents with and without dyslexia $(N=90)$

\begin{tabular}{|c|c|c|c|c|c|c|}
\hline \multirow[b]{2}{*}{ Behavioral Characteristics } & \multicolumn{2}{|c|}{$\begin{array}{l}\text { Dyslexia } \\
\text { Noncase } \\
(n=62)\end{array}$} & \multicolumn{2}{|c|}{$\begin{array}{c}\text { Dyslexia } \\
\text { Case } \\
(n=28)\end{array}$} & \multirow[b]{2}{*}{$F(1,88)$} & \multirow[b]{2}{*}{$\eta^{2}$} \\
\hline & $M$ & $S D$ & $M$ & $S D$ & & \\
\hline Reading & 1.77 & 0.85 & 3.26 & 1.10 & $48.82 *$ & 0.36 \\
\hline Writing & 1.76 & 1.02 & 3.38 & 1.01 & $48.56^{*}$ & 0.36 \\
\hline Composition & 1.97 & 1.05 & 3.46 & 1.06 & $38.61 *$ & 0.31 \\
\hline Memory and organization & 1.93 & 1.01 & 3.41 & 0.96 & $43.06^{*}$ & 0.33 \\
\hline Learning motivation & 2.25 & 1.21 & 3.65 & 1.06 & $27.81 *$ & 0.24 \\
\hline Internalizing behavior & 1.63 & 0.71 & 2.37 & 0.83 & $19.01 *$ & 0.18 \\
\hline Externalizing behavior & 1.43 & 0.60 & 2.46 & 1.08 & $33.52 *$ & 0.28 \\
\hline
\end{tabular}

Note: The maximum for each Behavior Checklist of Specific Learning Difficulties in Reading and Writing for Junior Secondary School Students score was 5. Case-noncase classification is based on the criteria using scores of the Hong Kong Test of Specific Learning Difficulties in Reading and Writing for Junior Secondary School Students (Chung et al., 2007). The $F$ tests are follow-up analyses of variance tests after the overall test in multivariate analysis of variance, and they are evaluated at the $.05 / 2$ or .025 level of significance.

$* p<.001$.

empirical scale scores of reading-related behavioral characteristics to determine whether differences between adolescents with and without dyslexia on each of the seven scores were significant. Table 3 summarizes the results of the analysis. Using the Bonferroni procedure, all seen scores of reading-related behavioral characteristics for adolescents with dyslexia were significantly higher than those for adolescents without dyslexia.

Similar results were obtained in a discriminant analysis using the whole BCLJS scale to predict membership in the dyslexic group. The overall results were significant, Wilks $\lambda=0.64, \chi^{2}(1, n=90)=38.87, p<.001$, indicating that the BCL-JS significantly differentiated adolescents with dyslexia from those without dyslexia. The dyslexic group had higher mean score $(M=3.14, S D=0.84)$ than that of the nondyslexic group $(M=1.82, S D=0.80)$. With prior probabilities based on group sizes for classification, the discriminant function correctly classified $82.2 \%$ of the 90 students.

\section{Screening for dyslexia}

To effect a simple decision rule for probable dyslexia case-noncase classification for further follow-up assessment, a cutoff score was sought using receiver operating characteristic curve analysis, plotting sensitivity (correct identification of adolescents with dyslexia as cases) against false positives (incorrect identification 
Table 4. Sensitivity and specificity in screening for dyslexia using different cutoff scores on reading-related behavioral characteristics $(N=90)$

\begin{tabular}{ccccc}
\hline \hline & \multicolumn{5}{c}{ Percentage } \\
\cline { 2 - 5 } Behavioral Characteristics & \multicolumn{5}{c}{} \\
\cline { 2 - 5 } Average Score (Positive if $>$ ) & Sensitivity & Specificity & False Negative & False Positive \\
\hline 2.13 & 89 & 74 & 11 & 26 \\
2.15 & 89 & 76 & 11 & 24 \\
2.17 & 89 & 77 & 11 & 23 \\
2.18 & 89 & 79 & 11 & 21 \\
2.27 & 89 & 79 & 11 & 21 \\
$\mathbf{2 . 4 4}$ & $\mathbf{8 6}$ & $\mathbf{8 1}$ & $\mathbf{1 4}$ & $\mathbf{1 9}$ \\
2.54 & 82 & 81 & 18 & 19 \\
2.59 & 79 & 81 & 21 & 19 \\
2.72 & 79 & 82 & 21 & 18 \\
2.85 & 75 & 82 & 25 & 18 \\
2.89 & 71 & 82 & 29 & 18 \\
\hline \hline
\end{tabular}

Note: The maximum for the overall Behavior Checklist of Specific Learning Difficulties in Reading and Writing for Junior Secondary School Students average scores was 5. Sensitivity is a measure of the ability to call positive (a case) those who are adolescents with dyslexia. Specificity is a measure of the ability to call negative (a noncase) those who are adolescents without dyslexia. False negative is an adolescent with dyslexia but is declared to be one without dyslexia. False positive is an adolescent without dyslexia but is declared to be one with dyslexia.

of adolescents without dyslexia as cases), both variables being in percentages. Table 4 presents the results of the analysis. Average scores of the BCL-JS were computed for each student and a cutoff score of 2.44 , that is, regarding a student with ratings above 2.44 as positive or a probable case, achieved a reasonably good sensitivity of $85.7 \%$. This cutoff also resulted in a reasonably good specificity of $80.6 \%$ in correctly identifying adolescents without dyslexia as noncases.

\section{DISCUSSION}

In order to make effective remedial provisions to dyslexic children and adolescents, teachers and related parties need a cost-effective measure to identify at-risk cases. Because literacy difficulties and specific cognitive deficits pertinent to dyslexia could be readily observed at the behavioral level (Frith, 1997), we developed the BCL-JS. On the basis of the checklist, teachers could obtain a brief profile of their students' reading-related behavioral characteristics by observing their everyday behaviors. This study describes the development and validation of the checklist and offers some evidence for adequate reliability and validity of the newly developed measure.

We conducted exploratory factor analyses on teachers' ratings on the checklist, and seven distinct constructs emerged. We constructed individual scales from the checklist on the basis of the items within each construct, and this resulted in seven 
subscales: reading, writing, composition, memory and organization ability, learning motivation, internalizing behavior, and externalizing behavior. All the scales in the checklist showed good internal consistency reliabilities. The construct validity of the BCL-JS was supported by its significant relations with criterion measures. The correlation analyses indicated that all seven constructs of the BCL-JS significantly correlated with students' performances on all tests on cognitive skills (except orthographic knowledge) and literacy as measured by the HKT-JS. This group of participants was relatively strong in orthographic knowledge as compared with their other cognitive skills. A mean composite score of 10.02 suggests that their orthographic skills are comparable to the general population (population mean $=10.0$ ). We believe that orthographic knowledge is more important for Chinese young readers' literacy development than it is in adolescent readers. This study revealed that all seven scores of reading-related behavioral characteristics of the BCL-JS could significantly differentiate adolescents with dyslexia from those without dyslexia. The discriminant analysis also showed that the BCL-JS had a high rate of correct classification $(82.2 \%)$. These findings lent support to the reliability and validity of the BCL-JS as a screening tool for Chinese junior secondary school students at risk for dyslexia. Considering that behavioral checklists seldom have amazing hit rates, the present findings of over $80 \%$ hit rate could be deemed satisfactory for an initial screening tool. The consequences of missing a case may be more detrimental than having a false alarm. With the help of the behavioral checklist, we believe that the rate of false alarms would be drastically lowered.

In comparison to the study conducted by Chan et al. (2003) on Chinese elementary students, we found that behavioral indicators of reading and writing ability as well as memory and organizational ability had high discriminative abilities to distinguish dyslexia cases and noncases for both children and adolescents. One interesting difference between Chan et al. (2003) and the present study was that the behavioral characteristics of reading and writing emerged as one single factor in Chan et al. (2003), whereas reading and writing emerged as two distinct factors in this study. Chan, Ho, Tsang, Lee, and Chung (2006) examined the readingwriting connection in Chinese children with dyslexia. They found that the magnitude of the correlations between reading and writing appeared to decrease with age. Consistent with this finding, the two distinct factors for reading and writing in our study may reflect developmental differences in reading-writing connection between children and young adolescents. Reading and writing might be connected through other age-related variables. More studies based on longitudinal data might further evaluate the possible differences and underlying factors in relation to the reading-writing connection.

Chan et al. (2004) found that children with and without dyslexia could not be differentiated by their social/emotional characteristics. In contrast, our study revealed that social/emotional behavioral characteristics, namely, internalizing behavior and externalizing behavior, could significantly predict the dyslexic membership in young adolescents. Internalizing behavior problems are characterized by an overcontrol of emotions. These problems include social withdrawal, demand for attention, feelings of worthlessness or inferiority, and dependency (Achenbach \& Edelbrock, 1978; McCulloch, Wiggins, Joshi, \& Sachdev, 2000). In general, children and adolescents with learning disabilities exhibited significantly lower 
self-concept and lower perceived academic competence than their peers without disabilities (Ayres, Cooley, \& Dunn, 1990; Bear, Clever, \& Proctor, 1991; Mulcahy, 1990; Raviv \& Stone, 1991). While students with learning problems manifested a higher risk of depression (Hall \& Halls, 1989; Hayes \& Sloat, 1988; Huntington \& Bender, 1993; Rourke, Young, \& Leenaars, 1989), the incidence of depression was more prevalent for adolescents (Maag \& Behrens, 1989; Wright-Strawderman $\&$ Watson, 1992). As the peer group takes on increasing importance in young adolescence, these internalizing problems may be exacerbated as children grow older.

Adolescents are vulnerable to feelings of being different and increasingly evaluate themselves through the eyes of others. While peer relationships assume cardinal importance in adolescents' self-concept, those with learning disabilities are in particular vulnerable because they are generally weaker in diverse aspects of social competence (Calhoun \& Beattie, 1987; Fine, 1987; Ritter, 1989; Sater \& French, 1989; Toro, Weissberg, Guare, \& Lievenstein, 1990). For instance, they performed worse than those without disabilities on nonverbal perception (Kavale \& Forness, 1996; Swanson \& Malone, 1992), and they were not competent at generating optimal solutions to social dilemma (Tur-Kaspa \& Bryan, 1993). Therefore, it is not surprising that these students exhibited more problems in interpersonal relationships and were less socially accepted than students without learning disabilities (Houck, Engelhard, \& Geller, 1989; LaGreca \& Stone, 1990; Roberts \& Zubrick, 1993; Schneider \& Yoshida, 1988; Shondrick, Serafica, Clark, \& Miller, 1992; Stone \& LaGreca, 1990; Wiener, Harris, \& Shirer, 1990). Problems in social relationships may in turn generate more internalizing problems, such as low selfesteem, anxiety, loneliness, and depression. Increasing demand on reading skills in higher levels of education may further aggravate the problems.

In addition to the increasing prevalence of internalizing problems, externalizing problems also appeared to increase with age from childhood to adolescence (Bryan, Pearl, \& Herzog, 1989). Externalizing behavior problems are characterized by an undercontrol of emotions, including difficulties with interpersonal relationships and rule breaking as well as displays of irritability and belligerence (Achenbach \& Edelbrock, 1978; Hinshaw, 1992). Out of academic failures and frustrations, adolescents with learning disabilities would exhibit more impulsive behavior, delinquency, and negative aggression than their age peers (Pearl, Bryan, \& Herzog, 1990; Perlmutter, 1987; Safran \& Safran, 1987). Pearl and Bryan (1992) suggested that adolescents easily succumbed to peer pressure to engage in misconduct because they particularly longed for friendships at this stage of development. Moreover, their inappropriate behavior may also be the result of their insensitivity to social cues (Pearl \& Bryan, 1992). After all, one probable consequence of externalizing behavior is that they may be subjected to continual social isolation (Mishna, 1996), peer rejection (Kuhne \& Wiener, 2000; Ochoa \& Olivarez, 1995), and loneliness (Margalit, 1998). In the present cross-sectional study, it is to be noted that elevated internalizing and externalizing behaviors may not be observed in the same individuals across time. We need further longitudinal study to examine this.

Both Chan et al. (2004) and Jorm et al. (1986) found that children with and without learning disabilities could not be differentiated in terms of social/emotional 
characteristics. However, as children enter adolescence, they may encounter more social problems and emotional hardship, which may become more observable signs of underlying reading problems. Consistent with this view, this study revealed that behavioral indicators in social and emotional domains, namely, internalizing and externalizing behavior, were useful for teachers to identify young adolescents at risk for dyslexia.

Sex differences in the association between behavior problems and dyslexia have been found in some (e.g., Maughan, Pickles, Hagell, Rutter, \& Yule, 1996) but not all studies (e.g., Boetsch et al., 1996, Lamm, \& Epstein, 1996). Consistent with the latter studies, no significant gender differences were observed in both the dyslexic and nondyslexic groups in this study.

Another area that was not addressed in the study conducted by Chan et al. (2003) was the use of learning motivation as one of the behavioral indicators. Motivation plays a crucial role in influencing students' reading behavior (Lorch \& van den Broek, 1997; Oldfather, 2002; Wigfield, 1997). Students with reading problems usually demonstrate poor academic self-concept (Chapman \& Tummer, 2003) and lack intrinsic interest in reading (van Kraayenoord \& Schneider, 1999). They tend to blame themselves for failure and attribute success to uncontrollable external causes such as luck (Borkowski \& Muthukrishna, 1992; Chan, 1994; Palladino, Poli, Masi, \& Marcheschi, 2000). On the basis of reviewing a number of studies, Gibb, Alloy, and Walshaw (2006) suggested that attribution style was relatively flexible when children were younger and appeared to become more fixed around the age of 12 years. As children with reading difficulties go from primary to secondary education, inflexible attribution styles as well as repeated experience of failures may discourage them to make constructive effort to remedy the worsening situation. This study revealed that the motivational issue of young adolescents was one of the behavioral manifestations of their underlying reading problems.

We could see the unique value of the present study based on the preceding discussion. Empirical evidence has showed that the use of behavioral checklists for dyslexic adolescents is rare in the literature. It may be partly due to the reason that dyslexic cases have already been identified when they are in their childhood, especially in countries where dyslexia has been widely recognized in the general public for a long time. However, this study suggested that the influences of dyslexia on adolescents were merely restricted not only to reading and writing domains but also extend to learning motivation, social, and emotional areas. There is an educational implication that teaching practices and remedial provisions for children and adolescents with dyslexia should be carefully tailored to their developmental needs.

We also believe that the identification instrument of dyslexia reported in this study could be applicable to other Chinese communities because its development was based on research studies conducted with Chinese dyslexic individuals in different Chinese communities (including Mainland China and Hong Kong). However, the instrument may require some adaptations because people in Mainland China and Taiwan learn to read Chinese characters with a phonemic coding system (Pinyin) or an onset-rime system (Zhu-Yin-Fu-Hao), respectively, as an aid, whereas people in Hong Kong learn to read Chinese characters in a more holistic manner with a look-and-say approach. Because the investigation of dyslexia and 
the development of service provision to dyslexic individuals are relatively new in the Chinese population, up till now the identification instrument reported here is the only standardized instrument of developmental dyslexia available in Chinese. More research on the instrument validation in other Chinese communities is warranted in the future. Educators should not stop at effective identification. The ultimate goal of identification is to facilitate intervention. A recent study reported that training in oral language, morphological awareness, orthographic skills, and syntactic skills were beneficial for children who learned to read Chinese, especially for struggling readers (Ho et al., 2012). A tiered intervention curriculum with these skill components is being implemented in Hong Kong primary and secondary schools.

\section{Directions for future research}

Reliability of a measure can be thought of in terms of stability over time and contexts as well as by internal consistency. Although internal consistency of the behavioral checklist is high, future examinations on its test-retest reliability are necessary. It would also be informative to carry out longitudinal studies. Children rated by teachers on the checklist could receive comprehensive testing both at the time of the initial ratings and some years later. Long-term follow-up on children would be essential to determine whether the measure has a strong predictive value over time.

Children's problem behaviors are not necessarily pervasive across settings. Comparisons between information provided by both parents and teachers would be a direction for future study. Parents and teachers are both valuable sources of information as an initial step in the assessment process because they are likely to perceive different aspects of the child/adolescent to give a more comprehensive portrayal (Sattler, 1992). Teachers may view students' behavior through a lens that may be highly affected by classroom expectations and school culture. Moreover, they observe students within a group setting in a single context for a few hours a day. In contrast, parents have the unique perspective of watching their children in diverse settings and observing their children's development over many years. Thus, including both parents and teachers as informants at the time of initial screening for dyslexia would be an invaluable addition to the assessment process. Further exploration is necessary to determine the most effective way to incorporate both parent and teachers ratings.

\section{CONCLUSION}

The importance of timely intervention for dyslexia calls for the development of a reliable and valid screening tool for Chinese students in Hong Kong. We consider the BCL-JS to be an efficient and practical measure of students' readingrelated behavioral characteristics. The behavior checklist is not intended to replace comprehensive diagnosis for dyslexia but rather to identify children at risk of failure for a range of reading-related behavior. This study has demonstrated that the checklist carries an excellent capacity to accurately distinguish between young Chinese adolescents with dyslexia and those without. With some adaptations, we 
believe that the instrument could be applicable to other Chinese communities as well. As a consequence of the availability of the screening checklist, teachers would feel empowered to identify young adolescents with reading problems and to use this information as pointers for appropriate remedial interventions.

\section{ACKNOWLEDGMENTS}

The present study was funded through the READ \& WRITE: A Jockey Club Learning Support Network from the Hong Kong Jockey Club Charities Trust. Special thanks are due to Suk-han Lee and Suk-man Tsang for their valuable support and consultation throughout the project.

\section{REFERENCES}

Achenbach, T. M. (1991). Manual for the Child Behavior Checklist/4-18. Burlington, VT: University of Vermont, Department of Psychiatry.

Achenbach, T. M., \& Edelbrock, C. S. (1978). The classification of child psychopathology: A review and analysis of empirical efforts. Psychological Bulletin, 85, 1275-1301.

Achenbach, T. M., \& Edelbrock, C. (1983). Manual for the Child Behavior Checklist and Revised Child Behavior Profile. New York: Queen City Printers.

Achenbach, T. M., \& Rescorla, L. A. (2001a). Manual for the ASEBA school-age forms and profiles. Burlington, VT: University of Vermont, Research Center for Children, Youth, and Families.

Achenbach, T. M., \& Rescorla, L. A. (2001b). Manual for the ASEBA preschool forms and profiles. Burlington, VT: University of Vermont, Research Center for Children, Youth, and Families.

Ayres, R., Cooley, E., \& Dunn, C. (1990). Self-concept, attribution, and persistence in learning disabled students. Journal of School Psychology, 28, 153-163.

Bear, G. G., Clever, A., \& Proctor, W. A. (1991). Self-perceptions of nonhandicapped children and children with learning disabilities in integrated classes. Journal of Special Education, 24, 409-426.

Beitchman, J. H., \& Young, A. R. (1997). Learning disorders with a special emphasis on reading disorders: A review of the past 10 years. Journal of the American Academy of Child \& Adolescent Psychiatry, 36, 1020-1032.

Benasich, A., Curtiss, S., \& Tallal, P. (1993). Language, learning and behavioral disturbances in childhood: A longitudinal perspective. Journal of American Academy of Child \& Adolescent Psychiatry, 32, 585-594.

Bender, L. (1946). Instructions for the use of the Visual Motor Gestalt Test. New York: American Orthopsychiatric Association.

Bender, W. N. (1987). Behavioral indicators of temperament and personality in the inactive learner. Journal of Learning Disabilities, 20, 301-305.

Bender, W. N., \& Wall, M. E. (1994). Social-emotional development of students with learning disabilities. Learning Disability Quarterly, 17, 323-341.

Blyth, D. A., Simmons, R. G., \& Bush, D. (1978). The transition into early adolescence: A longitudinal comparison of youth in two educational contexts. Sociology of Education, 51, 149-162.

Boetsch, E. A., Green, P. A., \& Pennington, B. F. (1996). Psychosocial correlated of dyslexia across the life span. Development and Psychopathology, 8, 539-562.

Borkowski, J. G., \& Muthukrishna, N. (1992). Moving metacognition into the classroom: "Working models" and effective strategy teaching. In M. Pressley, R. K. Harris, \& J. T. Guthrie (Eds.), Promoting academic competence and literacy in school (pp. 477-501). San Diego, CA: Academic Press.

Bradley, L., \& Bryant, P. (1978). Difficulties in auditory organization as a possible cause of reading backwardness. Nature, 271, 746-747.

Bryan, T., Pearl, R., \& Herzog, A. (1989). Learning disabled adolescents' vulnerability to crime: Attitudes, anxieties, experiences. Learning Disabilities Research, 5, 51-60. 
Burden, R. (2005). Dyslexia and self-concept: Seeking a dyslexic identity. London: Whurr.

Calhoun, M. L., \& Beattie, J. (1987). School competence needs of mildly handicapped adolescents. Adolescence, 22, 555-563.

Chan, L. K. S. (1994). Relationship of motivation, strategic learning and reading achievement in grades 5, 7, and 9. Journal of Experimental Education, 62, 319-340.

Chan, D. W., Ho, C. S.-H., Tsang, S., Lee, S., \& Chung, K. K. H. (2003). Reading-related behavioral characteristics of Chinese children with dyslexia: The use of Teachers' Behavior Checklist in Hong Kong. Annals of Dyslexia, 53, 300-323.

Chan, D. W., Ho, C. S.-H., Tsang, S., Lee, S., \& Chung, K. K. H. (2004). Screening for Chinese children with dyslexia in Hong Kong: The use of Teachers' Checklist. Educational Psychology, 24, 811-824.

Chan, D. W., Ho, C. S.-H., Tsang, S., Lee, S., \& Chung, K. K. H. (2006). Exploring the readingwriting connection in Chinese children with dyslexia in Hong Kong. Reading and Writing, 19, 543-561.

Chan, D. W., Ho, C. S.-H., Tsang, S., Lee, S., \& Chung, K. K. H. (2010). Teachers' checklist on reading-related behavioral characteristics of Chinese primary students: A Rasch measurement model analysis. Australian Journal of Learning Disabilities, 15, 151-170.

Chan, W. S., \& Ho, C. S.-H. (2002). The concomitance of dyslexia and emotional/behavioral problems: A study of Hong Kong children. Unpublished manuscript, University of Hong Kong.

Chapman, J. W., \& Tummer, W. F. (2003). Reading difficulties, reading-related self-perceptions, and strategies for overcoming negative self-beliefs. Reading and Writing Quarterly, 19, 5-24.

Chen, X., Anderson, R. C., Li, W. L., Hao, M. L., Wu, X. C., \& Shu, H. (2004). Phonological awareness of bilingual and monolingual Chinese children. Journal of Educational Psychology, 96, 142-151.

Chow, B. W., McBride-Chang, C., Cheung, H., \& Chow, C. S. (2008). Dialogic reading and morphology training in Chinese children: Effects on language and literacy. Developmental Psychology, 44, 233-244.

Chung, K. K. H., Ho, C. S.-H., Chan, D. W., Tsang, S., \& Lee, S. (2007). The Hong Kong Test of Specific Learning Difficulties in Reading and Writing for Junior Secondary School StudentsHKT-JS manual. Hong Kong: Hong Kong Specific Learning Difficulties Research Team.

Chung, K. K. H., Ho, C. S. H., Chan, D. W. O., Tsang, S. M., \& Lee, S. H. (2011). Cognitive skills and literacy performance of Chinese adolescents with and without dyslexia. Reading and Writing, $24,835-859$.

Coon, K. B., Waguespack, M. M., \& Polk, M. J. (1994). Dyslexia screening instrument. New York: Psychological Corporation.

DeFrancis, J. (1989). Visible speech: The diverse oneness of writing systems. Honolulu, HI: University of Hawaii Press.

Fine, E. (1987). Are we preparing adolescents with learning disabilities to cope with social issues? Journal of Learning Disabilities, 24, 413-420.

Frith, U. (1997). Brain, mind and behavior in dyslexia. In C. Hulme \& M. J. Snowling (Eds.), Dyslexia: Biology, cognition and intervention (pp. 1-19). London: Whurr.

Gibb, B., Alloy, L., \& Walshaw, P. (2006). Predictors of attributional style change in children. Journal of Abnormal Child Psychology, 34, 408-422.

Glascoe, F. P., Martin, E. D., \& Humphrey, S. (1990). A comparative review of developmental screening tests. Pediatrics, 86, 547-554.

Gresham, F. M. (1982). Misguided mainstreaming: The case for social skills training with handicapped children. Exceptional Children, 48, 422-433.

Hall, C. W., \& Halls, D. (1989). Depressive symptomatology in learning disabled and nonlearning disabled students. Psychology in the Schools, 26, 359-364.

Hamada, R. S., \& Tomikawa, S. (1986). Discriminant validity of the Windward Rating Scale: Screening for learning disabilities. Educational and Psychological Measurement, 46, 1083-1093.

Hayes, M. K., \& Sloat, R. S. (1988). Learning disability and suicide. Academic Therapy, 23, 469475.

Heiervang, E., Stevenson, J., Lund, A., \& Hugdahl, K. (2001). Behavior problems in children with dyslexia. Nordic Journal of Psychiatry, 55, 251-256.

Hellendoorn, J., \& Ruijssenaars, W. (2000). Personal experiences and adjustment of Dutch adults with dyslexia. Remedial and Special Education, 21, 227-239. 
Hinshaw, S. P. (1992). Externalizing behavior problems and academic underachievement in childhood and adolescence: Causal relationships and underlying mechanisms. Psychological Bulletin, $111,127-155$.

Ho, C. S.-H. (2010). Understanding reading disability in Chinese: From basic research to intervention. In M. H. Bond (Ed.), Handbook of Chinese psychology (2nd ed., pp. 109-121). New York: Oxford University Press.

Ho, C. S.-H., \& Bryant, P. (1997a). Phonological skills are important in learning to read Chinese. Developmental Psychology, 33, 946-951.

Ho, C. S.-H., \& Bryant, P. (1997b). Learning to read Chinese beyond the logographic phase. Reading Research Quarterly, 32, 276-289.

Ho, C. S. H., Chan, D. W. O., Lee, S. H., Tsang, S. M., \& Luan, V. H. (2004). Cognitive profiling and preliminary subtyping in Chinese developmental dyslexia. Cognition, 91, 43-75.

Ho, C. S.-H., Chan, D. W., Tsang, S., \& Lee, S. (2000a). The Hong Kong Specific Learning Difficulties Behavior Checklist (for primary school pupils) manual. Hong Kong: Hong Kong Specific Learning Difficulties Research Team.

Ho, C. S.-H., Chan, D. W., Tsang, S., \& Lee, S. (2000b). The Hong Kong Test of Specific Learning Difficulties in Reading and Writing (HKT-SpLD) manual. Hong Kong: Hong Kong Specific Learning Difficulties Research Team.

Ho, C. S.-H., Chan, D. W., Tsang, S., \& Lee, S. (2002a). The cognitive profile and multipledeficit hypothesis in Chinese developmental dyslexia. Developmental Psychology, 38, 543553.

Ho, C. S.-H., Chan, D. W., Tsang, S., \& Lee, S. (2002b). The Hong Kong Specific Learning Difficulties Behavior Checklist (for Primary One pupils). Hong Kong: Hong Kong Specific Learning Difficulties Research Team.

Ho, C. S.-H., Lo, L.-Y., Chan, D., Chung, K., Tsang, S.-M., \& Lee, S.-H. (2009). The Hong Kong Behaviour Checklist of Specific Learning Difficulties in Reading and Writing for Junior Secondary School Students (BCL-JS). Hong Kong: Hong Kong Specific Learning Difficulties Research Team.

Ho, C. S. H., Wong, W. L., \& Chan, W. S. (1999). The use of orthographic analogies in learning to read Chinese. Journal of Child Psychology and Psychiatry, 40, 393-403.

Ho, C. S.-H., Wong, Y. K., Yeung, P. S., Chan, D. W. O., Chung, K. K. H., Lo, S. C., et al. (2012). The core components of reading instruction in Chinese. Reading and Writing, 25, 857886.

Houck, C. K., Engelhard, J., \& Geller, C. (1989). Self-assessment of learning disabled and nondisabled college students: A comparative study. Learning Disabilities Research, 5, 61-67.

Huang, H. S., \& Hanley, J. R. (1997). A longitudinal study of phonological awareness, visual skills and Chinese reading acquisition among first-graders in Taiwan. International Journal of Behavioral Development, 20, 249-268.

Hulme, C., \& Snowling, M. (1992). Phonological deficits in dyslexia: A "sound" reappraisal of the verbal deficit hypothesis? In N. N. Singh \& I. L. Beale (Eds.), Progress in learning disabilities (pp. 270-301). New York: Springer-Verlag.

Humphrey, N., \& Mullins, P. M. (2002). Personal constructs and attribution for academic success and failure in dyslexia. British Journal of Special Education, 29, 196-203.

Huntington, D. D., \& Bender, W. N. (1993). Adolescents with learning disabilities at risk? Emotional well-being, depression, suicide. Journal of Learning Disabilities, 26, 159-166.

Jorm, A. F., Share, D. L., Matthews, R., \& McLean, R. (1986). Behavior problems in specific readingrelated retarded and general reading backward children: A longitudinal study. Journal of Clinical Psychology and Psychiatry, 27, 33-43.

Kavale, K. A., \& Forness, S. R. (1996). Social skill deficits and LD: A meta-analysis. Journal of Learning Disabilities, 29, 226-237.

Kuhne, M., \& Wiener, J. (2000). Stability of social status of children with and without learning disabilities. Learning Disability Quarterly, 23, 64-75.

LaGreca, A. M., \& Stone, W. L. (1990). LD status and achievement: Confounding variable in the study of children's social status, self-esteem, and behavioral functioning. Journal of Learning Disabilities, 23, 483-490.

Lamm, O., \& Epstein, R. (1996). Specific reading impairment-Are they to be associated with emotional difficulties? Journal of Learning Disabilities, 25, 605-615. 
Ching et al.: Dyslexia behavior checklist

Leong, C. K. (1973). Reading in Chinese with reference to reading practices in Hong Kong. In J. Downing (Ed.), Comparative reading: Cross-national studies of behavior and processes in reading and writing (pp. 383-402). New York: Macmillan.

Lichtenstein, R., \& Ireton, H. (1984). Preschool screening: Identifying young children with developmental and educational problems. Orlando, FL: Grune \& Stratton.

Liu, I. M., Chuang, C. J., \& Wang, S. C. (1975). Frequency count of 40,000 Chinese words. Taipei: Lucky Books.

Lorch, Jr., R. F., \& van den Broek, P. (1997). Understanding reading comprehension: Current and future contributions of cognitive science. Contemporary Educational Psychology, 22, 213-246.

Maag, J. W., \& Behrens, J. T. (1989). Depression and cognitive self-statements of learning disabled and seriously emotionally disturbed adolescents. Journal of Special Education, 23, 17-27.

Margalit, M. (1998). Loneliness and coherence among preschool children with learning disabilities. Journal of Learning Disabilities, 31, 173-181.

Margolis, H., Sheridan, R., \& Lemanowicz, J. (1981). The efficiency of Myklebust's Pupil Rating Scale for detecting reading and arithmetic difficulties. Journal of Learning Disabilities, 14, 267-268, 302.

Mash, E. J., \& Terdal, I. G. (Eds.). (1997). Assessment of childhood disorders (3rd ed.). New York: Guilford Press.

Mash, E. J., \& Wolfe, D. A. (2002). Abnormal child psychology (2nd ed.). Belmont, CA: Wadsworth.

Mattingly, I. G. (1972). Reading, the linguistic process and linguistic awareness. In J. Kavanagh \& I. Mattingly (Eds.), Language by ear and by eye (pp. 133-147). Cambridge, MA: MIT Press.

Maughan, B., Pickles, A., Hagell, A., Rutter, M., \& Yule, W. (1996). Reading problems and antisocial behaviour: Developmental trends in comorbidity. Journal of Child Psychology and Psychiatry, 37, 405-418.

McBride-Chang, C., Chow, B. W.-Y., Zhong, Y.-P., Burgess, S., \& Hayward, W. (2005). Chinese character acquisition and visual skills in two Chinese scripts. Reading and Writing, 18, 99128.

McBride-Chang, C., Shu, H., Zhou, A. B., Wat, C. P., \& Wagner, R. K. (2003). Morphological awareness uniquely predicts young children's Chinese character recognition. Journal of Educational Psychology, 95, 743-751.

McBride-Chang, C., Wagner, R. K., Muse, A., Chow, B. W.-Y., \& Shu, H. (2005). The role of morphological awareness in children's vocabulary acquisition in English. Applied Psycholinguistics, $26,415-435$.

McConaughty, S. H. (1986). Social competence and behavioral problems of learning disabled boys aged 12-16. Journal of Learning Disabilities, 19, 101-106.

McConaughy, S. H., \& Ritter, D. R. (1985). Social competence and behavioral problems of learning disabled boys aged 6-11. Journal of Learning Disabilities, 18, 547-553.

McCulloch, A., Wiggins, R. D., Joshi, H. E., \& Sachdev, D. (2000). Internalizing and externalizing children's behavior problems in Britain and the U.S.: Relationships to family resources. Children \& Society, 14, 368-383.

McKinney, J. D. (1989). Longitudinal research on the behavior characteristics of children with learning disabilities. Journal of Learning Disabilities, 22, 141-150.

McKinney, J. D., \& Feagans, L. (1984). Academic and behavioral characteristics of learning disabled children and average achievers: Longitudinal studies. Learning Disability Quarterly, 7, 251264.

Mishna, F. (1996). Finding their voice: Group therapy for adolescents with learning disabilities. Learning Disabilities Research and Practice, 11, 249-258.

Mulcahy, R. (1990). Perceived competence, self-concept, and locus of control for high ability students, as compared to average and learning disabled students. Canadian Journal of Special Education, 6, 42-49.

Ochoa, S. H., \& Olivarez, A. (1995). A meta-analysis of peer rating sociometric studies of pupils with learning disabilities. Journal of Special Education, 29, 1-20.

Oldfather, P. (2002). Learning from students about overcoming motivation problems in literacy learning: A cross-study analysis and synthesis. Reading Research Quarterly, 18, 343-353.

Olson, R. K., Rack, J. P., \& Forsberg, H. (1990, September). Profiles of abilities in dyslexics and reading-level-matched controls. Poster session presented at the meeting of the Rodin Remediation Academy, Boulder, CO. 
Palladino, P., Poli, P., Masi, G., \& Marcheschi, M. (2000). The relation between metacognition and depressive symptoms in preadolescents with learning disabilities: Data in support of Borkowski's model. Learning Disabilities Research and Practice, 15, 142-149.

Pearl, R., \& Bryan, T. (1992). Students' expectations about peer pressure to engage in misconduct. Journal of Learning Disabilities, 25, 582-585, 597.

Pearl, R., Bryan, T., \& Herzog, A. (1990). Resisting or acquiescing to peer pressure to engage in misconduct: Adolescents' expectations of probable consequences. Journal of Youth and Adolescents, 19, 43-55.

Perlmutter, B. F. (1987). Delinquency and learning disabilities: Evidence for compensatory behavior and adaptation. Journal of Youth and Adolescence, 16, 89-95.

Psychological Corporation. (1981). Hong Kong Wechsler Intelligence Scale for Children manual. New York: Author.

Qian, Y., Lee, T., \& Soong, F. K. (2004). Use of tone information in continuous Cantonese speech recognition. Paper presented at Speech Prosody 2004 International Conference, March, Nara, Japan.

Raviv, D., \& Stone, C. A. (1991). Individual differences in the self-image of adolescents with learning disabilities: The roles of severity, time of diagnosis, and parental perceptions. Journal of Learning Disabilities, 24, 602-611, 629.

Reynolds, C. R., \& Kamphaus, R. W. (1992). BASC: Behavioral Assessment System for Children manual. Circle Press, MN: American Guidance Services.

Richman, N., Stevenson, J., \& Graham, P. (1982). Preschool to school: A behavioral study. San Diego, CA: Academic Press.

Ritter, D. R. (1989). Social competence and problem behavior of adolescent girls with learning disabilities. Journal of Learning Disabilities, 22, 460-461.

Roberts, C., \& Zubrick, S. (1993). Factors influencing the social status of children with mild academic disabilities in regular classrooms. Exceptional Children, 59, 192-202.

Rourke, B. P., Young, G. C., \& Leenaars, A. A. (1989). A childhood learning disability that predisposes those afflicted to adolescent and adult depression and suicide risk. Journal of Learning Disabilities, 22, 169-175.

Sabornie, E. J. (1985). Social mainstreaming of handicapped students: Facing an unpleasant reality. Remedial and Special Education, 6, 12-16.

Safran, S. P., \& Safran, J. S. (1987). Behavioral contagion and manageability: Learning disability and regular education teachers' perspectives. Journal of Learning Disabilities, 209, 439-440, 447.

Salter, R., \& Smythe, I. (1997). The international nook of dyslexia. London: World Dyslexia Network Foundation and European Dyslexia Association.

Sanson, A. (2006). Reading disabilities with and without behavior problems at 7-8 years: Prediction from longitudinal data from infancy to 6 years. Child Psychology and Psychiatry, 37, 529-541.

Sater, G. M., \& French, D. C. (1989). A comparison of the social competences of learning disabled and low achieving elementary-aged children. Journal of Special Education, 23, 29-42.

Sattler, J. M. (1992). Assessment of children (3rd ed.). San Diego, CA: Jerome M. Sattler.

Schneider, M., \& Yoshida, R. K. (1988). Interpersonal problem-solving skills and classroom behavioral adjustment in learning-disabled adolescents and comparison peers. Journal of School Psychology, 26, 24-34.

Shankweiler, D., Liberman, I. Y., Mark, L. S., Fowler, C. A., \& Fischer, F. W. (1979). The speech code and learning to read. Journal of Experimental Psychology: Human Learning and Memory, 5, 531-545.

Shelton, T. L., \& Barkley, R. A. (1994). Critical issues in the assessment of attention deficit disorders in children. Topics in Language Disorders, 14, 26-41.

Shondrick, D. D., Serafica, F. C., Clark, P., \& Miller, K. G. (1992). Interpersonal problem solving and creativity in boys with and boys without learning disabilities. Learning Disability Quarterly, 15, 95-102.

Shu, H., McBride-Chang, C., Wu, S., \& Liu, H. Y. (2006). Understanding Chinese developmental dyslexia: Morphological awareness as a core cognitive construct. Journal of Educational Psychology, 98, 122-133.

Simmons, R. G., Blyth, D. A., Van Cleave, E. F., \& Bush, D. M. (1979). Entry into adolescence: The impact of school culture, puberty, and early dating on self-esteem. American Sociological Review, 44, 948-967. 
Siok, W. T., \& Fletcher, P. (2001). The role of phonological awareness and visual-orthographic skills in Chinese reading acquisition. Developmental Psychology, 37, 886-899.

Stone, W. L., \& LaGreca, A. M. (1990). The social status of children with learning disabilities. Journal of Learning Disabilities, 23, 32-37.

Swanson, H. L., \& Malone, S. (1992). Social skills and LD: A meta-analysis. School Psychology Review, 21, 427-443.

Taft, M., \& Chung, K. (1999). Using radicals in teaching Chinese characters to second language learners. Psychologia, 42, 243-251.

Toro, P. A., Weissberg, R. P., Guare, J., \& Lievenstein, N. L. (1990). A comparison of children with and without learning disabilities on social problem-solving skill, school, behavior, and family background. Journal of Learning Disabilities, 23, 115-120.

Tur-Kaspa, H., \& Bryan, T. (1993). Social attributions of students with learning disabilities. Exceptionality, 4, 229-243.

Undheim, A. M. (2003). Dyslexia and psychosocial factors: A follow-up study of young Norwegian adults with a history of dyslexia in childhood. Nordic Journal of Psychiatry, 57, 221-226.

van Kraayenoord, C. E., \& Schneider, W. E. (1999). Reading achievement, metacognition, reading self-concept and interest: A study of German students in grades 3 and 4. European Journal of Psychology of Education, 54, 305-324.

Wagner, W. G. (2003). Counseling, psychology, and children: A multidimensional approach to intervention. Upper Saddle River, NJ: Merrill.

Wang, M., Liu, Y., \& Perfetti, C. A. (2004). The implicit and explicit learning of orthographic structure and function of a new writing system. Scientific Studies of Reading, 8, 357-379.

Wiener, J., Harris, P. J., \& Shirer, C. (1990). Achievement and social-behavioral correlates of peer status in LD children. Learning Disability Quarterly, 13, 114-127.

Wigfield, A. (1997). Children's motivations for reading and reading engagement. In J. T. Guthrie \& A. Wigfield (Eds.), Reading engagement: Motivating readers through integrated instruction (pp. 14-33). Newark, NJ: International Reading Association.

Wright-Strawderman, C., \& Watson, B. L. (1992). The prevalence of depression symptoms in children with learning disabilities. Journal of Learning Disabilities, 25, 258-264. 